\title{
Etiology of Alternaria Leaf Spot of Cotton in Southern New Mexico
}

\author{
Yi Zhu1 ${ }^{1}$, Phillip Lujan', Srijana Dura ${ }^{1}$, Robert Steiner ${ }^{2}$, Jinfa Zhang ${ }^{3}$, and Soum Sanogo ${ }^{1, \dagger}$ \\ ${ }^{1}$ Department of Entomology, Plant Pathology and Weed Science, New Mexico State University, Las Cruces, NM 88003 \\ ${ }^{2}$ Department of Economics, Applied Statistics \& International Business, New Mexico State University, Las Cruces, NM 88003 \\ ${ }^{3}$ Department of Plant and Environmental Science, New Mexico State University, Las Cruces, NM 88003
}

\begin{abstract}
Alternaria leaf spot (caused by Alternaria spp.) is one of the most common foliar diseases of cotton (Gossypium spp.) and occurs in most cottongrowing regions of the world. In surveys of commercial cotton fields, Alternaria leaf spot has increased in prevalence and incidence in southern New Mexico due to favorable environmental conditions in recent years. Incidence, severity, and etiology of leaf spot of cotton in southern New Mexico were determined. Fourteen cotton fields with plants exhibiting leaf spot symptoms were evaluated in October and November 2016, when plants were at late growth stage. Disease incidence was $100 \%$ in 13 of the fields, and averaged $70 \%$ in the 14th field. Average disease severity index for all

features and PCR using universal primers ITS4/ITS5 and primers targeting the plasma membrane ATPase gene. Colonies of all 14 isolates were olive green with distinct white margins and relatively small spores when compared with reference isolates of large-spored species. All 14 isolates were identified as A. alternata. The fungus grew on potato dextrose agar from 5 to $35^{\circ} \mathrm{C}$, and optimum growth occurred at temperatures between 20 and $30^{\circ} \mathrm{C}$. Cotton plants inoculated with selected isolates of A. alternata displayed symptoms similar to those observed under field conditions. This is the first report of A. alternata as a causal agent of Alternaria leaf spot on cotton in southern New Mexico.
\end{abstract} fields ranged from 21.5 to 87.0. For identification of the causal agent, 14 isolates (one from each field) were characterized based on morphological
Keywords: Alternaria, leaf spot, Gossypium spp., identification
Cotton (Gossypium L.) is a fiber and food crop of high economic importance worldwide. Among more than 80 cotton production countries, the United States ranks third after China and India, and it is the leading exporter of cotton in the world (USDA-ERS 2012). Other major producers include Pakistan, Brazil, and Turkey. In the United States, cotton is produced in 17 states from Virginia to California, known as the 'Cotton Belt' of the U.S.A. There are two types of cotton grown commercially in the United States: Gossypium hirsutum and G. barbadense (Womach 2004). G. hirsutum, also called Upland cotton, is grown in warm climates and contributes more than $95 \%$ of the cotton production in the United States (Said et al. 2013). G. barbadense, commonly known as extra-long staple cotton, American Pima, or Sea-Island cotton, is favored for superior fiber length, strength, and fineness (Said et al. 2013), but its low yield has limited its production to less than $5 \%$ of the total cotton production (Lee 1984). In New Mexico, cotton is a vital crop with a value of approximately $\$ 30.6$ million in 2016 (USDA-NASS 2017).

Cultivation and production of cotton can be seriously constrained by several fungal, bacterial, and viral diseases (Kirkpatrick and Rothrock 2001). About 80 to $90 \%$ of cotton diseases are foliar diseases (Gulhane and Gurjar 2011). Alternaria leaf spot is one of the most notable foliar diseases of cotton, occurring in most cotton growing regions worldwide including Israel, India, China, Egypt, Russia, Zimbabwe, and the United States (Ellis and Holliday 1970). It was first reported in the United States in 1918 and has spread to all cotton growing regions (Faulwetter 1918). Alternaria leaf spot is generally associated with late-season development of cotton plants or senescing plant tissues. It is characterized by small, brown, circular lesions on the leaves that are surrounded by distinct purple margins. Similar symptoms can be observed on buds, flowers,

${ }^{\dagger}$ Corresponding author: S. Sanogo; ssanogo@nmsu.edu

Funding: Agricultural Experiment Station, New Mexico State University.

The author(s) declare no conflict of interest.

Accepted for publication 24 January 2019.

(c) 2019 The American Phytopathological Society and bolls in mature plants. As the disease progresses, the lesions expand and become dry and gray in the center, exhibiting shot-hole symptoms on leaves. These spots may coalesce and occupy large leaf areas resulting in severe defoliation, affecting cotton yield and quality (Watkins 1981). Numerous outbreaks of the disease have occurred in many cotton producing regions in the world and caused yield losses up to $25 \%$ in Israel and a yield reduction up to $60 \%$, with an average yield loss of $35.6 \%$ in the Karnataka state of India (Bashi et al. 1983; Padaganur et al. 1989; Rotem et al. 1988). With favorable environmental conditions and increased cultivation of susceptible cotton cultivars, Alternaria leaf spot has also become more serious in the United States, particularly in Arizona with yield losses up to 10 to $15 \%$ (Cotty 1987a). The disease has also been observed with severe defoliation in Texas and New Mexico as well as in Tennessee, Alabama, Mississippi, and Louisiana in recent years (Allen 2011; Hagan and Sikora 2013; Howard et al. 1997; Price et al. 2013; Woodward 2016; Woodward et al. 2007; Zhu et al. 2018).

The principal causal agent of Alternaria leaf spot is considered as Alternaria macrospora Zimm (Ellis and Holliday 1970), which was first described by Zimmerman in 1904 (Robeson et al. 1985). A. alternata (Nees: Fr.) Keissler is also commonly found on cotton but is reported as a weak pathogen causing leaf spots (Rotem et al. 1988). In the United States, the identity of the pathogen responsible for the disease is not completely clear. In Arizona, highly virulent isolates of A. macrospora were identified as the causal agent of Alternaria leaf spot on Upland cotton Acala-90 (Cotty 1987a), and several outbreaks of Alternaria leaf spot caused by A. macrospora occurred during 1982 to 1984 (Cotty 1987b). Woodward et al. (2007) reported A. macrospora as the causal agent of Alternaria leaf spot in Texas. Recently, the disease has also been observed in New Mexico with increased incidence and severity, resulting in severe defoliation in the late cotton-growing season (Zhu et al. 2018). However, there has been no previous systematic research on the prevalence (occurrence among fields), incidence (occurrence within a field), severity (percent infected leaf area), or etiology of this disease in the state. Proper identification of the pathogen causing Alternaria leaf spot of cotton in New Mexico is critical for the efficient management of this disease.

Historically, tremendous effort has been invested into the identification of Alternaria spp. based on morphological characteristics, including cultural morphology, shape and size of conidia, septation, beak formation, branching patterns of conidial chains, and sporulation 
patterns (Simmons 2007; Simmons and Roberts 1993). It is very easy to distinguish large-spored Alternaria spp. from small-spored catenulate species since the conidia are distinct and easy to recognize. However, it is very difficult to differentiate the small-spored species within the A. alternata species group due to overlap of many of the morphological characters (Andrew et al. 2009).

In addition to morphological identification, molecular approaches and phylogenic analyses have been used for identification and characterization of the genus Alternaria based on DNA sequence data of ribosomal DNA (rDNA), nuclear internal transcribed-spacer regions (ITS), the mitochondrial ribosomal large subunit (mtLSU), the mitochondrial small subunit (mtSSU), and translation elongation factor $(T E F)$, beta-tubulin, endopolygalacturonase genes, glyceraldehyde-3-phosphate dehydrogenase ( $g p d$ ) gene, plasma membrane ATPase, Alternaria major allergen (Alt al), calmodulin, gapdh, and anonymous genomic regions OPA1-3, OPA2-1, and OPA10-2 (Andrew et al. 2009; Lawrence et al. 2013; Luo et al. 2017; Patel and Zhang 2017; Peever et al. 2004; Pryor and Bigelow 2003; Pryor and Gilbertson 2000; Woudenberg et al. 2013; Zhu and Xiao 2015). Phylogenic analyses have differentiated large-spored from small-spored Alternaria species (Andrew et al. 2009; Peever et al. 2004). However, it is still challenging to separate the small-spored species, including A. alternata, A. tenuissima, A. arborescens, and $A$. infectoria due to poor resolution in the genetic loci (Andrew et al. 2009). The highly conserved ITS sequence has been widely used for identification and classification of Alternaria species. However, only A. infectoria could be distinguished from other small-spored Alternaria species, while A. alternata, A. tenuissima, and $A$. arborescens are indistinguishable especially for $A$. alternata and $A$. tenuissima, indicating that ITS sequence data cannot differentiate these taxa (Basim et al. 2017; Luo et al. 2017; Peever et al. 2004; Pryor and Bigelow 2003). Phylogenetic analyses conducted by Lawrence et al. (2013) reported five protein-coding genes ( $g p d$, actin, plasma membrane ATPase, Alt al, and calmodulin) were informative in identifying Alternaria species. Among these genes, the plasma membrane ATPase and calmodulin loci were proposed as the most suitable genetic markers for molecular identification of small-spored Alternaria (Lawrence et al. 2013, 2016). Therefore, the ITS region and plasma membrane ATPase gene sequences were selected to classify Alternaria isolates from cotton in this study.

The objectives of this study were to (1) evaluate the incidence and prevalence, as well as severity of Alternaria leaf spot on cotton in southern New Mexico, and (2) characterize the causal agent of Alternaria leaf spot of cotton using morphological and molecular phylogenetic approaches.

\section{Materials and Methods}

Field survey of Alternaria leaf spot. A field survey of Alternaria leaf spot on cotton was carried out at several locations in Doña Ana County, one of the major cotton-producing counties in southern New Mexico in October and November 2016 when plants were at late growth stage. Fourteen cotton fields were arbitrarily selected and surveyed in the north and south of Las Cruces (Table 1), the major city in Doña Ana County. In each field, 10 plants in each of four corners (southwest, southeast, northwest, and northeast) were arbitrarily selected, and the incidence and severity of the disease were recorded for each corner. Disease incidence was defined as the percentage of plants displaying Alternaria-type leaf spot symptoms out of the total number of plants examined in a field (Teng and James 2002). Averages of disease incidence and severity were computed for each field by using the averages of each corner per field. Disease prevalence was defined as the percentage of fields exhibiting Alternaria-type leaf spot symptoms out of the total number of fields inspected (Sanogo and Carpenter 2006).

Disease severity was estimated using a disease rating scale of 0 to 5 (Bhat et al. 2013) based on a visually estimated percentage of infected leaf area as the following: $0=$ no disease; $1=$ $0.1-10.0 \%$ infected leaf area; $2=10.1-25.0 \%$ infected leaf area; $3=25.1-50.0 \%$ infected leaf area; $4=50.1-75.0 \%$ infected leaf area; and $5=>75.0 \%$ infected leaf area. Then, a disease severity index, ranging from 0 (for no symptom) to 100 (for the highest severity), was further calculated using the following formula (Park et al. 2008):

Disease severity index $(\mathrm{DSI})=$

$$
\frac{\sum(\text { score } \times \text { number of plants with the score }) \times 100}{\text { Total number of plants } \times \text { the highest score }}
$$

Isolation frequency of fungi associated with Alternaria leaf spot. To identify the pathogen associated with Alternaria leaf spot, 20 symptomatic leaves from 20 plants were collected from each corner in each field surveyed and further processed in the laboratory. Three leaves per corner were processed as follows. From each leaf, a piece $(3 \mathrm{~mm} \times 3 \mathrm{~mm})$ of tissue was cut from the margin of each of four lesions to provide 48 leaf pieces per field. The sampled leaf pieces were washed free of soil, surface sterilized in $10 \%$ sodium hypochlorite for $30 \mathrm{~s}$, then rinsed two to three times in distilled water. The leaf pieces were blotted dry with a paper towel and plated on acidified potato dextrose agar medium (APDA) to minimize bacterial growth in 9-cm-diameter Petri plates. Plates were incubated at $25^{\circ} \mathrm{C}$ for 5 to 7 days. Emerging mycelial colonies were transferred to fresh APDA for an additional 3 to 5 days to purify the cultures. Pure cultures were transferred and cultured on potato dextrose agar medium (PDA). Isolation frequency was defined as the percentage of

Table 1. Source of Alternaria isolates obtained from cotton leaves used in this study

\begin{tabular}{|c|c|c|c|c|c|}
\hline \multirow[b]{2}{*}{ Species } & \multirow[b]{2}{*}{ Isolate $^{\mathbf{a}}$} & \multirow[b]{2}{*}{ Location } & \multicolumn{2}{|c|}{ GenBank accession number } & \multirow{2}{*}{$\begin{array}{l}\text { Sample time } \\
(\mathrm{mm} / \mathrm{dd} / \mathrm{yyyy})\end{array}$} \\
\hline & & & ITS & ATPase & \\
\hline Alternaria alternata & Chamberino-NW & Chamberino, NM & MH032830 & МH079417 & $11 / 3 / 2016$ \\
\hline A. alternata & Anthony-NW & Anthony, NM & MH032824 & MH079411 & $11 / 3 / 2016$ \\
\hline A. alternata & Mesquite-NW & Mesquite, NM & MH032829 & MH079416 & $11 / 3 / 2016$ \\
\hline A. alternata & Baca-NW & Baca Road, NM & MH032828 & MH079415 & $10 / 27 / 2016$ \\
\hline A. alternata & Berino-NW & Berino, NM & MH032031 & MH079418 & $11 / 3 / 2016$ \\
\hline A. alternata & HW28-NW & Highway $28, \mathrm{NM}$ & MH032834 & MH079421 & $10 / 25 / 2016$ \\
\hline A. alternata & Rincon-NE & Rincon, NM & MH032827 & MH079414 & $10 / 27 / 2016$ \\
\hline A. alternata & Southwind-NW & Southwind Road, NM & MH032825 & MH079412 & $10 / 25 / 2016$ \\
\hline A. alternata & Fabian-NW & Fabian Garcia, NM & MH032833 & MH079420 & $10 / 25 / 2016$ \\
\hline A. alternata & Pajaro-NW & Pajaro Road, NM & MH032826 & MH079413 & $10 / 25 / 2016$ \\
\hline A. alternata & Lamesa-NW & La Mesa, NM & MH032832 & МH079419 & $10 / 25 / 2016$ \\
\hline A. alternata & OM-NW & Old Mesilla, NM & MH032822 & МH079409 & $10 / 27 / 2016$ \\
\hline A. alternata & M10-NW & Marker 10, NM & MH032823 & MH079410 & $10 / 26 / 2016$ \\
\hline A. alternata & L2 & Leyendecker, NM & MH032821 & МH079408 & $10 / 26 / 2016$ \\
\hline
\end{tabular}

a Isolates used for PCR amplification of the internal transcribed spacer region and the fragments of plasma membrane ATPase, for evaluation of the effect of temperature on mycelial growth, pathogenicity test on cotton plants, and morphological identification of Alternaria spp. 
lesions from which Alternaria-type colonies were isolated for each field.

Preservation of isolates. To obtain single-spore cultures, the method described by Zhu and Xiao (2015) was used with some modifications. Conidia were collected from 10-day-old sporulating colonies using a sterile spatula and then streaked onto $1 \%$ water agar plates. Then, the plates were incubated at room temperature (22 to $25^{\circ} \mathrm{C}$ ) for $20 \mathrm{~h}$, and the germinating conidia were selected under a microscope and transferred to fresh PDA plates. Single-spore isolates were grown on PDA for 7 to 10 days and stored in sterile distilled water at $4^{\circ} \mathrm{C}$. In total, 168 Alternaria isolates were obtained in this study. Identification of isolates was based on morphological characteristics and molecular phylogenetic analysis.

Morphological characterization of Alternaria isolates. Fourteen representative isolates (one isolate per field) were selected for morphological characterization (Table 1). To observe the colony morphology, selected isolates were cultured on PDA for 7 days at $25^{\circ} \mathrm{C}$ (Pryor and Michailides 2002). Colonies were then observed for color, margin, and texture. Colony color was determined according to color standards of Ridgway (1912). Colony texture was determined based on descriptions by Nobles (1948).

To determine sporulation patterns, isolates were cultured on PDA at $25^{\circ} \mathrm{C}$ in the light for 7 days. Then, a dissecting microscope was used to examine the cultures for characteristics of sporulation, including length of conidial chains, presence of elongated secondary conidiophores, and branching patterns of conidial chains occurred. For microscopic observations, slide-sized sterilized filter papers were moistened with sterile distilled water and placed on the top of slides. A rectangular cut $(2 \mathrm{~cm} \times 1 \mathrm{~cm})$ was made in the center of the filter paper and the cut-out piece was removed; this provided a rectangular window for easy observations on the glass slide. Mycelial plugs were placed on opposite ends of filter papers. Pictures of characteristic features such as conidia and conidial chains were taken under a compound microscope.

Effect of temperature on mycelial growth. The effect of temperature on mycelial growth of the 14 representative isolates was evaluated. Isolates were cultured on PDA at $25^{\circ} \mathrm{C}$ for 7 days and then, 1-cm-diameter mycelial plugs from the leading edges of colonies were transferred to 9-cm-diameter Petri dishes containing PDA. Inoculated plates were placed in plastic crispers and incubated at 5, $10,15,20,25,30$, and $35^{\circ} \mathrm{C}$ in the dark. There were three replicate plates used for each isolate at each temperature. This experiment was conducted twice. Colony diameter $(\mathrm{mm})$ for each plate was measured in two perpendicular directions after 3, 6, and 9 days of inoculation at each temperature. The measurements taken at each time for each isolate were averaged. Mean diameter was then used to calculate the area under the mycelial growth curve (AUMGC), which integrates mycelial growth over time (Tymon et al. 2016). AUMGC was calculated using the following formula:

$$
\text { AUMGC }=\sum_{i=1}^{n}\left[\frac{D_{i}-D_{i+1}}{2}\right]\left(T_{i+1}-T_{i}\right)
$$

where $D_{i}$ is the mean colony diameter at time $T_{i}$.

DNA extraction, PCR, and sequencing. The 14 selected isolates were cultured on PDA at $25^{\circ} \mathrm{C}$ for 7 days. Conidia and mycelia of each isolates were collected into a sterile microcentrifuge tube for DNA extraction. Genomic DNA of the isolates was extracted using DNeasy Plant Mini kit (Qiagen, Valencia, CA). The DNA pellet was suspended in $30 \mu \mathrm{l}$ deionized water and stored at $-80^{\circ} \mathrm{C}$ until further use. DNA concentrations were measured by spectrophotometer (Nanodrop 1000, ThermoScientific, Wilmington, U.S.A.). The nuclear rDNA internal transcribed spacer (ITS) region was amplified using primers ITS 4 (5'-TCCTCCGCTTATTGATATGC-3') and ITS 5 (5'-GGAAGTAAAAGTCGTAACAAGG-3') (Luo et al. 2017; White et al. 1990). Amplifications of fragments of plasma membrane ATPase (ATPDF1 5'-ATCGTCTCCATGACCGAGTTCG-3' and ATPDR1 5'-TCCGATGGAGTTCATGATAGCC-3') for 14 selected isolates were performed using primers ATPDF1/ATPDR1 (Lawrence et al. 2014). PCR amplification was conducted in a 20$\mu l$ reaction volume containing $1 \mu l$ genomic DNA, $5 \times$ buffer (Promega, Madison, WI), $1.5 \mathrm{mM} \mathrm{MgCl}_{2}$ (Promega), $0.2 \mathrm{mM}$ DNTP's (Promega), $1 \mathrm{mM}$ of each primer (Sigma, St. Louis, MO), 1 unit of Taq polymerase (Promega), and $12.8 \mu l$ deionized water. Thermal cycling parameters for the ITS region were as follows: initial denaturation for $5 \mathrm{~min}$ at $94^{\circ} \mathrm{C}$, followed by 35 cycles of denaturation at $94^{\circ} \mathrm{C}$ for $1 \mathrm{~min}$, annealing at $58^{\circ} \mathrm{C}$ for $1 \mathrm{~min}$ and extension at $72^{\circ} \mathrm{C}$ for $1 \mathrm{~min}$, then a final extension for $10 \mathrm{~min}$ at $72^{\circ} \mathrm{C}$. The thermal cycling parameters for the plasma membrane ATPase gene were as follows: initial denaturation for $30 \mathrm{~s}$ at $94^{\circ} \mathrm{C}$, followed by 35 cycles of denaturation at $94^{\circ} \mathrm{C}$ for $30 \mathrm{~s}$, annealing at $59^{\circ} \mathrm{C}$ for $30 \mathrm{~s}$ and extension at $72^{\circ} \mathrm{C}$ for $1 \mathrm{~min}$, then a final extension at $72^{\circ} \mathrm{C}$ for $5 \mathrm{~min}$ (Lawrence et al. 2013). Negative (no DNA) control was used in all PCR experiments. PCR products were then confirmed using a $1.2 \%$ agarose gel stained with $0.5 \mu \mathrm{g} / \mathrm{ml} \mathrm{SYBR}$ Green I Nucleic Acid Gel Stain (Sigma) electrophoresed with $1 \times$ TAE running buffer for 45 min at 110 volts. For molecular size standards, 100 bp (New England biolabs) ladder was used for all gels. Visualization of the amplified products separated by gel electrophoresis was performed with UV illumination. Amplified PCR products were purified using the Qiaquick PCR purification kit (Qiagen, Valencia, CA) according to kit protocols. After purification, PCR products were sent for sequencing at MC Lab in California using Sanger dideoxy sequencing technology and software. The sequenced DNA products were assembled and deposited to the National Center for Biotechnology Information (NCBI).

Phylogenetic analysis. The DNA sequences were assembled and manually edited using Geneious (version 9.1.3), then queried for high identity with Alternaria species for the ITS region and plasma membrane ATPase gene using BLASTN search (https://blast.ncbi. nlm.nih.gov/Blast.cgi) in NCBI GenBank (Table 2). The DNA

Table 2. Reference sequences of Alternaria spp. used for phylogenetic analyses in this study

\begin{tabular}{|c|c|c|c|}
\hline \multirow[b]{2}{*}{ Species } & \multirow[b]{2}{*}{ Isolate } & \multicolumn{2}{|c|}{ GenBank accession number } \\
\hline & & ITS $^{\mathbf{a}}$ & $\begin{array}{c}\text { Plasma membrane } \\
\text { ATPase }\end{array}$ \\
\hline $\begin{array}{l}\text { Alternaria } \\
\text { alternata }\end{array}$ & EGS 34-016 & AF347031.1 & JQ671874.1 \\
\hline A. alternata & X1432 & $*$ & KJ908223.1 \\
\hline A. alternata & BMP0463 & $*$ & JQ811981.1 \\
\hline A. alternata & SOK4 & KY484894.1 & $*$ \\
\hline A. alternata & X1048 & $*$ & KJ908230.1 \\
\hline A. alternata & $16 \mathrm{MC}$ & $*$ & MG740628.1 \\
\hline A. alternata & BMP0270 & $*$ & JQ811980.1 \\
\hline A. tenuissima & 093B & MF072676.1 & $*$ \\
\hline A. tenuissima & BMP0517 & $*$ & JQ811982.1 \\
\hline A. tenuissima & BMP0238 & $*$ & JQ811984.1 \\
\hline A. tenuissima & $3 . J 11$ & $*$ & KJ908258.1 \\
\hline A. tenuissima & X1309 & $*$ & KJ908241.1 \\
\hline A. arborescens & DN06 & KY781381.1 & $*$ \\
\hline A. arborescens & EGS 39-128 & AF347033.1 & JQ671880.1 \\
\hline A. arborescens & 40MC & $*$ & MG740635.1 \\
\hline A. arborescens & BMP3170 & $*$ & KY626545.1 \\
\hline A. arborescens & BMP0602 & $*$ & JQ811991.1 \\
\hline A. macrospora & DGG Ams1 & AF229469.1 & JQ671909.1 \\
\hline A. macrospora & MKP4 & KM514669.1 & $*$ \\
\hline A. zinniae & CBS 118.44 & $*$ & JQ671937.1 \\
\hline A. zinniae & CHHAZ1 & AF267135.1 & $*$ \\
\hline A. zinniae & CBS 299.79 & KJ718268.1 & $*$ \\
\hline A. carthami & CBS 635.80 & KJ718131.1 & JQ671904.1 \\
\hline A. tomotophila & CBS 109156 & $*$ & JQ671923.1 \\
\hline A. solani & ATCC 58177 & AF229475.1 & JQ671898.1 \\
\hline A. proteae & EGS 39-031 & $*$ & JQ671777.1 \\
\hline A. radicina & ATCC 96831 & AF229471.1 & JQ671851.1 \\
\hline
\end{tabular}

${ }^{\mathrm{a}}$ Internal transcribed spacer region. $*=$ Sequences not available in GenBank 
sequences obtained from this study have been deposited in GenBank (Table 1). Phylogenetic analyses were conducted for each of the ITS and plasma membrane datasets by using MUSCLE for multiple alignment, Gblocks for alignment curation, and maximum likelihood for construction of phylogenetic tree in by using MEGA (version 6 . 06). Branch stability was assessed with 1,000 bootstrap replications and branches were collapsed when branch support value was smaller than $70 \%$.

Pathogenicity test. The 14 selected isolates of Alternaria used in the molecular characterization were evaluated for pathogenicity. Isolates were cultured on PDA for 7 days and incubated at $25^{\circ} \mathrm{C}$. To induce sporulation, $5 \mathrm{ml}$ of sterile distilled water was added to each plate, mycelium were scraped off the surface of the medium with a sterile spatula, and the plates were placed in a culture-transfer hood to dry for 2 to $3 \mathrm{~h}$. After drying, the plates were covered with two layers of cheesecloth and placed in an incubator at $25^{\circ} \mathrm{C}$ for 2 days. Then, spores were collected by scraping off the surface of the medium with a sterile spatula, and dispensed into 50-ml falcon tubes containing sterile distilled water. Spore suspensions were filtered through four layers of cheesecloth. Concentrations of the spore suspensions were estimated using a hemocytometer and adjusted to $5 \times 10^{5}$ spores $/ \mathrm{ml}$.

Two genotypes of cotton (Upland: Acala 1517-08; Pima: DP 348) susceptible to Alternaria leaf spot were used for pathogenicity tests. Cotton seeds were planted into sterilized Miracle-Gro Moisture Control Potting Mix in 13-cm-diameter Styrofoam pots. Four seeds per pot were planted $2 \mathrm{~cm}$ below the surface of the soil. All pots were maintained in the greenhouse at 22 to $28^{\circ} \mathrm{C}$ and watered as needed. When cotton plants were at the stage of five to seven fully expanded leaves, they were inoculated with spore suspensions $\left(5 \times 10^{5}\right.$ spores $\left./ \mathrm{ml}\right)$. For each isolate tested, three replicate pots of each genotype of cotton were inoculated by spraying the foliage of each plant with $100 \mathrm{ml}$ of suspensions of each isolate until runoff. Plants serving as control were sprayed with sterile distilled water. Afterward, inoculated cotton plants were kept in clear plastic boxes, which had 1-cm depth of sterile water on the bottom to keep high relative humidity ( $>95 \%)$. Each plastic box was covered with a lid and placed in the laboratory at 22 to $25^{\circ} \mathrm{C}$ for 2 days, and then moved to the greenhouse. This experiment was conducted twice.

At 15 days after inoculation, disease severity was estimated for each plant using a rating scale described by Bashan et al. (1991) with some modifications: $0=$ no symptom; $1=1-20$ lesions/plant; $2=$ 21-70 lesions/plant; $3=71-140$ lesions/plant; $4=141-200$ lesions/plant; and $5=$ more than 200 lesions/plant, indicating heavy infection. Disease incidence was defined as the percentage of the inoculated cotton plants that developed leaf spot symptoms out of the total inoculated cotton plants. Disease severity was calculated by the formula mentioned previously. Disease incidence and severity data were subjected to analysis of variance (ANOVA) using PROC GLM in SAS statistical software (Version 9.4, SAS Institute, Carry, NC) with mean separation using least significant differences at $P<0.05$.

\section{Results}

Field survey of Alternaria leaf spot. According to climatic information available for the region of New Mexico where the field survey was done (Anonymous 2018), the monthly average high temperatures for the months of April through September, the active growing season, differed by 0.6 to $1.1^{\circ} \mathrm{C}$ across the locations surveyed while the monthly average low temperatures differed by 1.7 to $3.9^{\circ} \mathrm{C}$ for the same time interval. Average monthly precipitation across the locations investigated differed by 1.8 to $16.0 \mathrm{~mm}$. Alternaria leaf spot symptoms were observed in all fields, specifically, brown circular lesions, with distinct purple margins, on aboveground cotton plant parts including leaves, stems, and bolls. Disease prevalence was $100 \%$. Of the 14 fields surveyed, the average incidence of the disease in sampled plants was $100 \%$ in each of the 13 fields, and $70 \%$ in one field in Rincon (Table 3). However, more than $50 \%$ defoliation was present in the Rincon field due to defoliant spray being applied on cotton plants, which is common practice before harvesting. Average disease severity index (DSI) across all fields varied from approximately 21.5 to 87.0 (Table 3 ). The disease severity index of Alternaria leaf spot in the Pajaro field in Mesilla (87.0) was the highest among the 14 fields surveyed. The lowest and the second lowest disease severity index of Alternaria leaf spot were observed in the Rincon field and the Fabian Garcia field (34.0), respectively. The average disease severity index of Alternaria leaf spot in Berino and Chamberino fields were 44.0 and 44.5 , respectively. In the remaining fields, average disease severity index was approximately 70.0 .

Isolation frequency of fungi associated with Alternaria leaf spot. Isolations from sampled plants yielded Alternaria colonies and a few other fungal microorganisms including Penicillium and Aspergillus species. Alternaria colonies were the most frequently isolated across all fields with isolation frequency ranging from 70 to $100 \%$ (Table 3). Isolation frequency of Alternaria colonies was $100 \%$ in nine of the 14 fields surveyed. Mycelial colonies were similar across all nine fields and no other fungal organisms were isolated from infected leaves. In the Rincon field, Alternaria colonies were the least frequently isolated $(70 \%)$ from the diseased leaves. In the remaining fields (two in Las Cruces and one in Berino), isolation frequency of Alternaria recovered from sampled leaves ranged from 80 to $90 \%$.

Morphological characterization of Alternaria isolates. After 7 days growing on PDA, all 14 selected Alternaria isolates showed A. alternata-like morphology (Pryor and Michailides 2002). Mycelial colonies were olive green to dark olive green with a prominent

Table 3. Disease incidence, disease severity index of Alternaria leaf spot, and isolation frequency of Alternaria spp. from lesions on cotton plants in 14 commercial fields surveyed in southern New Mexico

\begin{tabular}{|c|c|c|c|c|c|}
\hline \multirow[b]{2}{*}{ Field } & \multicolumn{2}{|c|}{ Disease incidence $(\%)$} & \multicolumn{2}{|c|}{ Disease severity index } & \multirow[b]{2}{*}{ Isolation frequency $(\%)$} \\
\hline & Mean & $\overline{\text { Standard error }}$ & Mean & $\overline{\text { Standard error }}$ & \\
\hline Anthony & 100 & 0 & 73.5 & 1.73 & 95 \\
\hline Baca Road & 100 & 0 & 73.5 & 2.78 & 90 \\
\hline Berino & 100 & 0 & 44 & 3.09 & 82.5 \\
\hline Chamberino & 100 & 0 & 44.5 & 3.96 & 100 \\
\hline Fabian Garcia & 100 & 0 & 34 & 3.08 & 80 \\
\hline Highway 28 & 100 & 0 & 73 & 3.1 & 100 \\
\hline La Mesa & 100 & 0 & 56 & 3.25 & 100 \\
\hline Leyendecker & 100 & 0 & 64 & 1.91 & 100 \\
\hline Marker 10 & 100 & 0 & 67.5 & 3.33 & 100 \\
\hline Mesquite & 100 & 0 & 71 & 3.18 & 100 \\
\hline Old Mesilla & 100 & 0 & 72.5 & 3.62 & 100 \\
\hline Pajaro Road & 100 & 0 & 87 & 2.72 & 100 \\
\hline Rincon & 70 & 0.6 & 21.5 & 4.13 & 70 \\
\hline Southwind Road & 100 & 0 & 79.5 & 3.35 & 100 \\
\hline
\end{tabular}


white margin, and the colonies were over $80 \mathrm{~mm}$ in diameter on PDA after 9 days. Colony texture was felty to wooly (Fig. 1A). All isolates developed conidial chains of six to 14 conidia in length and secondary chains of one to six conidia in length (Fig. 1B and C). Conidial chains branched in a sympodial manner through the elongation of secondary conidiophores from distal terminal conidia cells. Conidia were typically ovate, ellipsoid, or obclavate in shape with a tapered beak.

Effect of temperature on mycelial growth. All 14 selected isolates grew on PDA at temperatures from 5 to $35^{\circ} \mathrm{C}$ (Fig. 2). The slope of the mycelial growth curve (AUMGC) increased with temperature from 5 up to $25^{\circ} \mathrm{C}$ and then decreased rapidly with increasing temperature. The optimal temperature of mycelial growth was $25^{\circ} \mathrm{C}$ and the optimum temperature range for mycelial growth was from
20 to $30^{\circ} \mathrm{C}$. Colony color became darker and colony margin became thinner as the temperature increased.

Phylogenetic analysis. Sequence analysis of the ITS region of the 14 selected isolates demonstrated $100 \%$ sequence identity with the A. alternata species group and the representative isolates used from the NCBI by BLAST search. In the phylogenetic analysis, the maximum-likelihood tree divided the 26 Alternaria isolates (14 isolates used in this study and 12 representative isolates from different Alternaria species within GenBank) into three groups (Fig. 3). Group 1 consisted of all 14 selected isolates belonging to A. alternata species group, the reference $A$. alternata isolates (EGS 34-016, SOK4), A. tenuissima (093B), and A. arborescens (EGS 39-128, DN06) with 99\% bootstrap support. Group 2 contained only one reference isolate, A. radicina (ATCC 96831). Group 3, with 99\% bootstrap

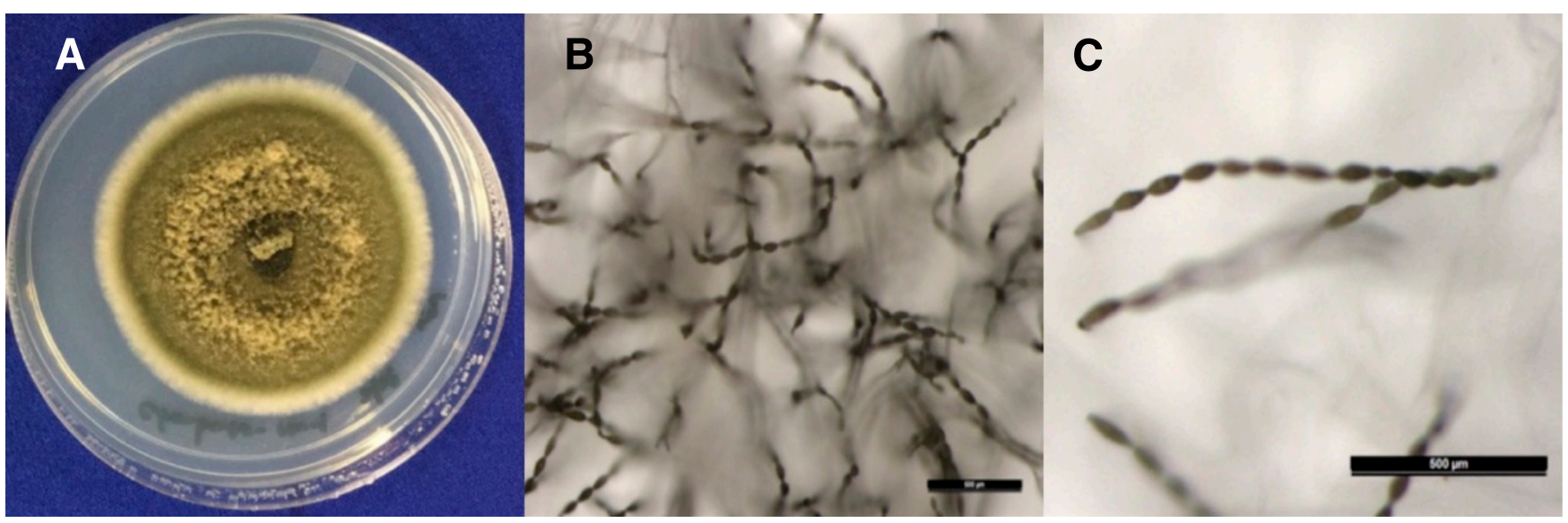

Fig. 1. Morphological characteristics of Alternaria colonies isolated from cotton. A, Colony morphology of Alternaria colonies on PDA after 7 days; B and C, sporulation pattern of Alternaria colonies on PDA after 7 days.
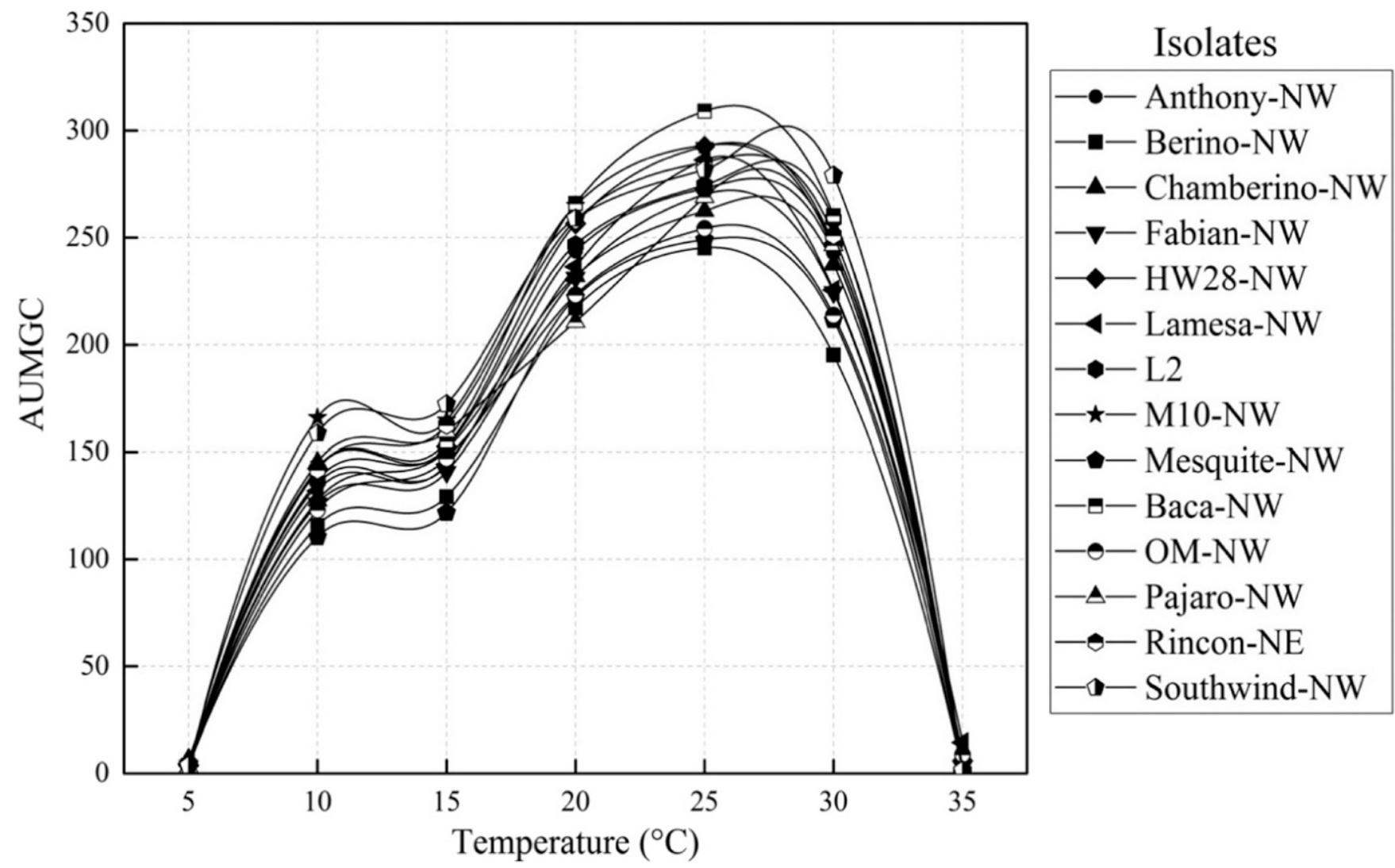

Fig. 2. Effect of temperature on mycelial growth of 14 isolates of Alternaria alternata. 
support, contained six representative large-spored isolates (A. zinniae CHHAZI, A. zinniae CBS 299.79, A. carthami CBS 635.80, A. macrospora DGG Ams1, A.macrospora MPK4, and A. solani ATCC 58177) as out-group isolates. Maximum likelihood analysis revealed that all of the Alternaria isolates were clearly distinct from out-group isolates with high support values. However, the phylogenetic analysis of ITS sequence could not differentiate $A$. alternata, $A$. tenuissima, and $A$. arborescens due to the lack of sequence variation.

A similar separation was obtained by analysis of ATPase gene. The maximum-likelihood tree separated the 35 isolates (14 isolates used in this study and 21 representative isolates from different Alternaria species within GenBank) into six groups (Fig. 4). In group 1, all 14 selected isolates were clustered with six A. alternata reference isolates (EGS 34-016, X1432, X1048, BMP0270, BMP0463, and $16 \mathrm{MC}$ ) and one A. tenuissima reference isolate (BMP0238) into two subgroups with $92 \%$ bootstrap support. Twelve of the selected isolates were grouped together with five A. alternata reference isolates (EGS 34-016, X1432, X1048, BMP0463, and 16MC) and one A. tenuissima reference isolate (BMP0238) with $89 \%$ bootstrap support in one subgroup while two of the selected isolates (PajaroNW and Rincon-NE) were grouped with one A. alternata reference isolate (BMP0270) in another subgroup. Group 2, with $98 \%$ bootstrap support, contained three A. tenuissima reference isolates (3. J11, X1309, and BMP0517). Group 3 contained four A. arborescens reference isolates (EGS 39-128, 40MC, BMP3170, and BMP0602) with $99 \%$ bootstrap support value in two subgroups. Group 4 contained five representative large-spored isolates (A. solani ATCC 58177, A. zinniae CBS 118.44, A. carthami CBS 635.80, A. tomatophila CBS 109156, and A. macrospora DGG Ams1). Group 5 contained only one isolate (A. radicina ATCC 96831), and Group 6 contained only one isolate (A. proteae EGS 39-031). Isolates in Groups 4, 5, and 6 could be considered as out-group isolates. Maximum likelihood analysis of plasma membrane ATPase gene revealed that all of the small-spored Alternaria isolates were clearly distinct from out-group isolates with high support values. Compared with

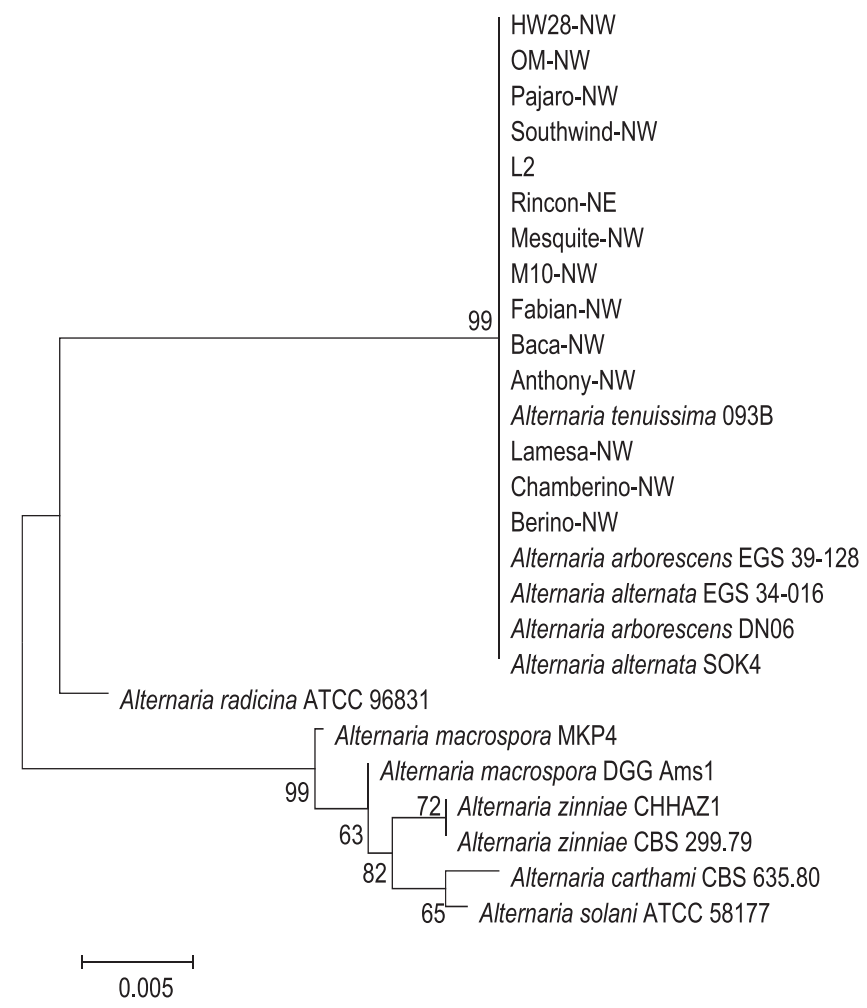

Fig. 3. Phylogenetic tree obtained by maximum-likelihood analysis of internal transcribed spacer 4 (ITS4) and 5 (ITS5) sequence. Sequences data for reference isolates were obtained from GenBank and accession numbers are listed in Table 2. Branch support values are shown at the nodes. the reference isolates, the phylogenetic analysis of plasma membrane ATPase gene could differentiate A. alternata and A. arborescens. However, it was not able to differentiate A. alternata and A. tenuissima because one reference isolate of $A$. tenuissima (BMP0238) was grouped into the same group with A. alternata. In this study, 14 selected isolates were clearly distinct from the large-spored species $A$. macrospora morphologically and molecularly (Lawrence et al. 2013; Pryor and Michailides 2002; Simmons 2007; Zhu and Xiao 2015). The ITS sequences of the 14 selected isolates were identical to the A. alternata reference isolate EGS 34-016. Moreover, all the selected Alternaria isolates showed A. alternata-like morphology, thus A. alternata was by far the most frequently isolated causal agent of Alternaria leaf spot on cotton. Thus, 14 selected isolates were identified as A. alternata.

Pathogenicity test. All of the 14 isolates of A. alternata were pathogenic on cotton. Inoculated cotton plants displayed symptoms similar to those found under field conditions (Fig. 5). No symptoms were observed on control plants. The average incidence of Alternaria leaf spot on both Upland and Pima cotton inoculated with the isolates of A. alternata was $100 \%$. The average disease severity index on Upland cotton Acala 1517-08 and Pima cotton DP 348 ranged from 26.0 to 65.0 and from 46.0 to 80.0 , respectively (Fig. 6). Overall, the average disease severity of Pima DP 348 was higher than that of Upland cotton Acala1517-08. ANOVA indicated no significant differences between the two replications, and thus the data were combined for further analyses. No significant interaction was detected $(P>0.05)$ between the isolates and cotton genotypes. ANOVA detected differences in pathogenicity among the 14 isolates of $A$.

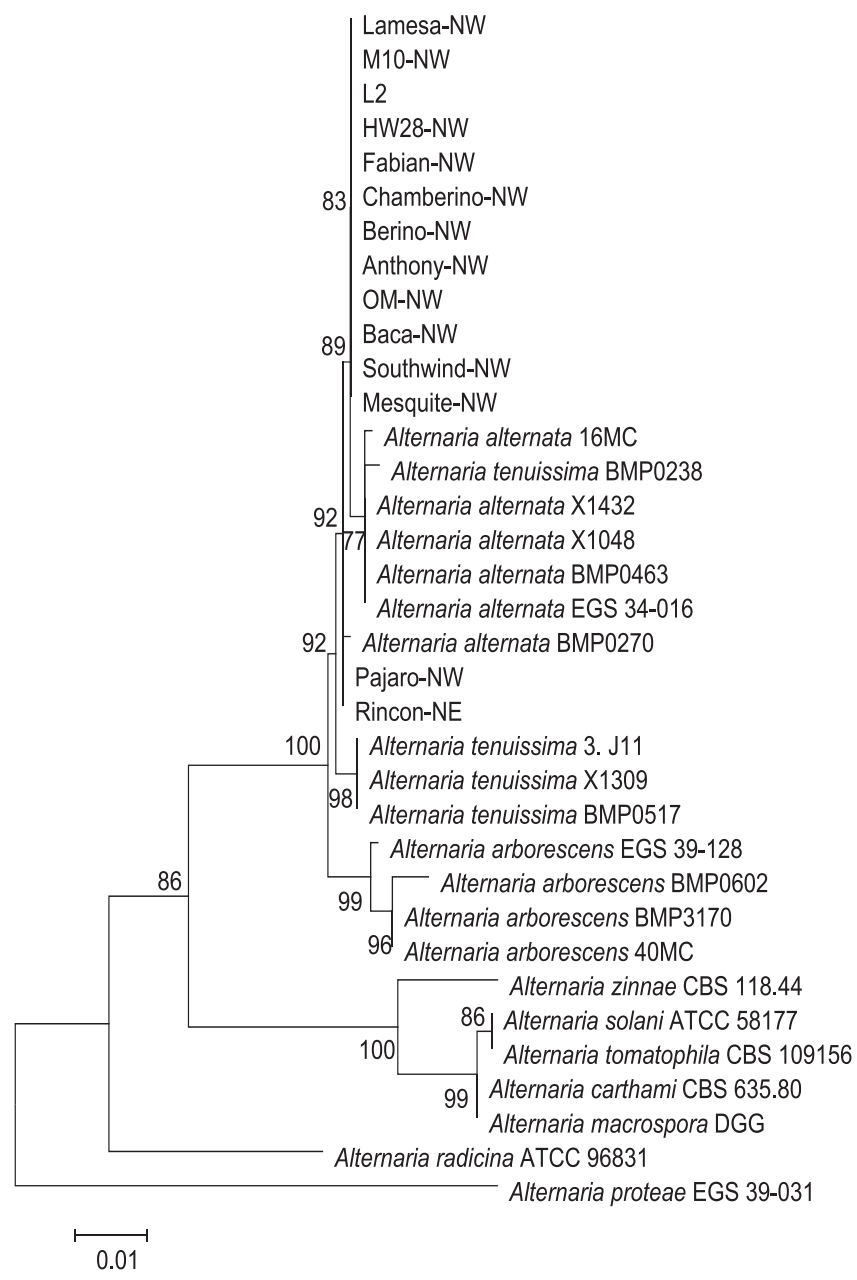

Fig. 4. Phylogenetic tree obtained by maximum-likelihood analysis of plasma membrane ATPase gene sequence. Sequences data for reference isolates were obtained from GenBank and accession numbers are listed in Table 2. Branch support values are shown at the nodes. 
alternata $(P<0.0001)$ and differences between Upland and Pima cotton when inoculated with $A$. alternata isolates $(P<0.0001$; Table 4).

\section{Discussion}

This study indicates that $A$. alternata is the predominant species present in the cotton production areas in southern New Mexico based on fungal morphological characteristics and molecular identification using phylogenetic analysis of multiple gene sequences. This is the first report of A. alternata as a causal agent of Alternaria leaf spot on cotton in southern New Mexico. This finding is in contrast with the literature reporting A. macrospora as the principal causal agent of Alternaria leaf spot in the United States (Cotty 1987b). Indeed, in the neighboring states of Arizona and Texas, A. macrospora is associated with Alternaria leaf spot. This disease survey was conducted for only one year in several fields across a broad geographical zone with varied environmental conditions, yet no A. macrospora was associated with Alternaria leaf spot, only A. alternata. Additional surveys conducted over several years are needed to further verify the role of A. alternata and A. macrospora in Alternaria leaf spot development in New Mexico.

Even though Alternaria leaf spot is the most common foliar disease of cotton, it is considered as a minor disease in many cotton production regions because the disease generally occurs at the end of the cropping season. This study showed Alternaria leaf spot symptoms caused by A. alternata are widely distributed late in the cottongrowing season (April through September) in New Mexico. Alternaria leaf spot has been observed in southern New Mexico with increased incidence and severity on cotton when favorable temperature and rainfall conditions occur (Cotty 1987b), but yield reductions caused by the disease have not been documented or reported. Continuing monitoring of the disease over multiple years is warranted to ascertain the impact of Alternaria leaf spot on cotton yield.

According to previous studies reporting yield loss associated with Alternaria leaf spot, the incidence of the disease was attributed to potassium deficiency and favorable environmental conditions (Cotty 1987b; Hillocks and Chinodya 1989). Potassium deficiency in the leaf at the time of infection by the Alternaria pathogen results in premature defoliation on cotton plants, and high humidity and cooler temperature may cause rapid and severe defoliation, leading to yield losses (Zhao et al. 2013). Our field surveys indicated that Alternaria leaf spot is prevalent in southern New Mexico and will probably become more prevalent and severe as the fungus can survive on crop debris in the soil. Necessary management of the disease should be taken to reduce the disease incidence and severity. Recommendations for control of Alternaria leaf spot include burying infected crop residues, fungicide applications, and use of resistant cultivars (Hillocks

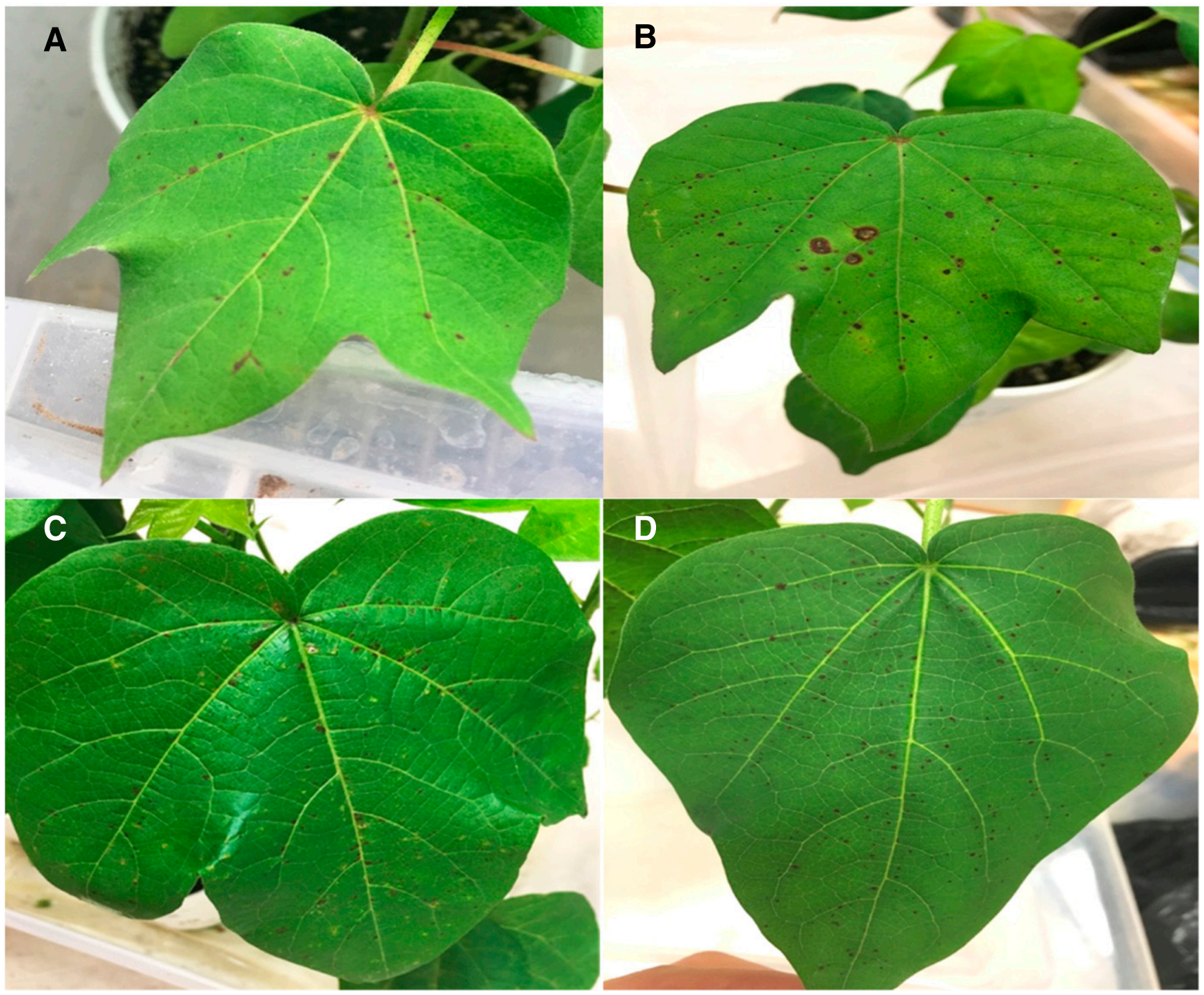

Fig. 5. Pathogenicity test on cotton plants inoculated with isolate O-NW-2 of Alternaria alternata. A, 7 days after inoculation on Upland cotton cultivar Acala 1517-08; B, 15 days after inoculation on Upland cotton cultivar Acala 1517-08; C, 7 days after inoculation on Pima cotton cultivar DP 348; D, 15 days after inoculation on Pima cotton cultivar DP 348. 
1991). Burying crop residues is a simple and feasible way to manage disease, but the effect on Alternaria leaf spot on cotton has not been examined. Several fungicides, such as pyraclostrobin and azoxystrobin, are used on cotton to manage Alternaria leaf spot in the southeastern United States. However, multiple applications of these fungicides are not recommended, possibly because of concerns of pathogen resistance (Hagan and Sikora 2013). No information on the use of fungicides for managing Alternaria leaf spot in New Mexico was collected during this survey. The use of resistant cultivars is the best approach to manage the disease. Currently, there are no commercial cotton cultivars that are completely resistant to A. alternata. Consequently, additional management practices for Alternaria leaf spot are needed.

Most studies on identification of Alternaria fungi have been conducted with a combination of morphological and molecular methods. In this study, a multiphasic approach was used for the characterization of Alternaria isolates collected from symptomatic cotton plants. Although it is easy to classify the large- and small-spored species groups based on distinct conidia and colony morphology, it is difficult to separate various species within the small-spored group because of high levels of similarity in morphological characteristics (Andersen and Thrane 1996; Lawrence et al. 2014; Zhu and Xiao 2015). In this study, incubation of single-spored colonies on PDA resulted in typical A. alternata morphological features. A previous study showed that the incubation on dichloran rose Bengal yeast extract sucrose agar (DRYES) could differentiate small-spored Alternaria species (Andersen and Thrane 1996; Andersen et al. 2001; Polizzotto et al. 2012) based upon colony features. Potato carrot agar (PCA), $0.05 \times$ PDA, or synthetic nutrient agar (SNA) were commonly used for observation of the sporulation patterns and PDA was used for observation of the colony features (Pryor and Michailides 2002; Rotondo et al. 2012; Woudenberg et al. 2013; Zhu and Xiao 2015). In this study, PDA was sufficient for morphological characterization of small-spored A. alternata. For characterization of sporulation patterns, our results showed conidial chains of A. alternata grown on PDA are usually six to 14 conidia in length and one to six conidia in length on secondary conidial chains. Of the several small-spored Alternaria spp., A. tenuissima and A. alternata have very similar morphological features regarding conidial chains and conidial characteristics when grown on PDA (Zhu and Xiao 2015). Colony colors and sporulation patterns of $A$. arborescens and $A$. infectoria grown on PDA are different from those of A. alternata species.

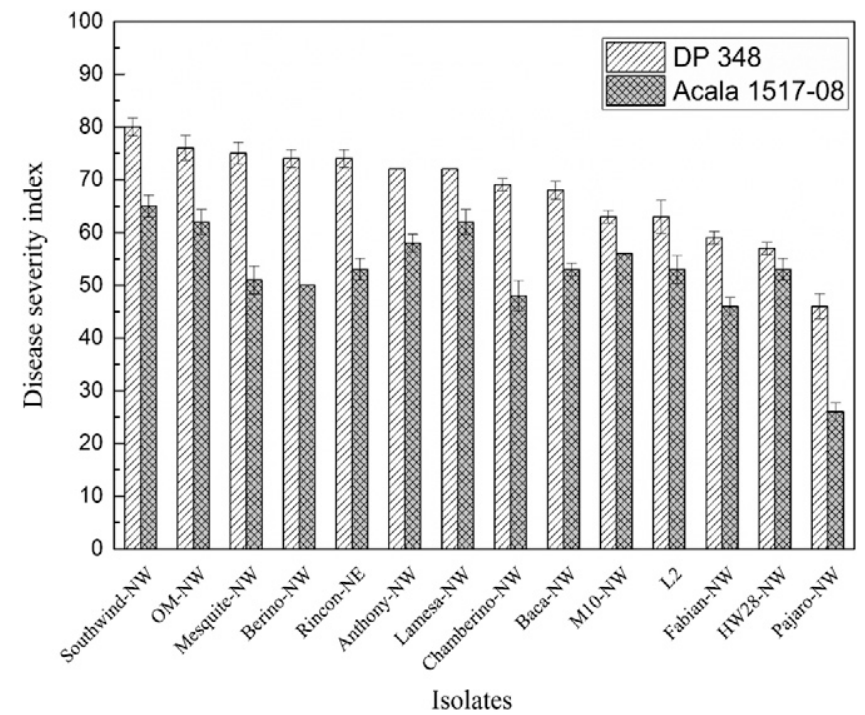

Fig. 6. Average disease incidence of Alternaria leaf spot on Upland cotton Acala 1517-08 and Pima cotton DP 348 inoculated with 14 isolates of Alternaria alternata. Bars on each column represent standard error of the mean incidence.
In order to clearly differentiate A. alternata from A. tenuissima, molecular approaches were used to complement morphological identifications. Phylogenetic analysis based on DNA sequence is a powerful tool for separation of small-spored species. Within small-spored Alternaria, the benefit of ITS sequence for species identification has been fiercely debated because several species share a high level of similarities in morphology; for example, A. alternata and A. tenuissima are $100 \%$ identical or nearly so (Lawrence et al. 2016). In this study, sequence analysis of the ITS region demonstrated $100 \%$ sequence identity to the A. alternata reference isolate SOK4 (as well as to reference sequences of $A$. tenuissima and $A$. arborescens). The phylogenetic analysis of the ITS region revealed that all selected A. alternata-like isolates were clustered in the same clade with A. alternata, A. tenuissima, and A. arborescens reference isolates. The results support earlier studies (Basim et al. 2017; Luo et al. 2017; Peever et al. 2004; Pryor and Bigelow 2003) that sequences of ITS regions do not provide sufficient variability to identify $A$. alternata species. Lawrence et al. (2013) suggested the plasma membrane ATPase gene is one of the most suitable markers for separating Alternaria species groups. In a recent study on Alternaria fruit rot of blueberry in California, plasma membrane ATPase gene distinguished A. alternata, A. tenuissima, and A. arborescens (Zhu and Xiao 2015), although two $A$. tenuissima reference sequences grouped with A. alternata in the A. alternata cluster (Zhu and Xiao 2015). In another study characterizing Alternaria isolates from pomegranates in California, phylogenetic analysis based on the sequence of plasma membrane ATPase gene was not able to differentiate between $A$. alternata and A. tenuissima (Luo et al. 2017). The phylogenetic analysis of plasma membrane ATPase gene in this study showed that 12 A. alternata-like isolates clustered within the same subgroup with five reference isolates of $A$. alternata and one A. tenuissima reference isolate, while the remaining two A. alternata-like isolates clustered within the other subgroup with one reference isolate of $A$. alternata in the main A. alternata cluster. Thus, the plasma membrane ATPase gene was not sufficient to separate A. alternata and A. tenuissima, and morphological characteristics were needed to distinguish the two species.

The identification of small-spored Alternaria species has been taxonomically difficult because they share very similar morphological characteristics (Andrew et al. 2009; Elfar et al. 2018; Luo et al. 2017). Simmons (1999) maintained that these species should not be merged into a single cluster since they were distinguishable taxa that exhibit discrete morphological characters. Generally, colony morphology and sporulation of $A$. arborescens was distinct from those of the other two small-spored species, A. alternata and A. tenuissima. Colony morphology of A. alternata and A. tenuissima, however, were similar, but sporulation was usually different and could be used to differentiate the two species (Simmons 1995; Zhu and Xiao 2015). However, recent phylogenetic studies have made significant changes to the systematic taxonomy. A multilocus phylogeny study conducted by Andrew et al. (2009) reported morphological identification was a poor predictor of phylogenetic lineage among small-spored Alternaria species. In their study, only $22 \%$ of isolates were classified in the A. arborescens group, and the remaining $78 \%$ of isolates were undifferentiated due to inconformity between morphology and phylogenetic lineage. They proposed a phylogenetic $A$. arborescens group and suggested that all other isolates be considered as A. alternata until more information could be used for species classification. Still another phylogenetic study using five highly variable loci revealed that three major

Table 4. Analysis of variance of pathogenicity of 14 isolates of Alternaria alternata on Pima and Upland cotton plants

\begin{tabular}{lrccr}
\hline Source & DF & Mean square & F value & Pr $>$ F \\
\hline Isolates & 13 & 307.760 & 16.08 & $<0.0001$ \\
Genotypes & 1 & 3210.290 & 167.7 & $<0.0001$ \\
Isolates * Genotypes & 13 & 38.440 & 2.01 & 0.0596 \\
Error & 28 & 19.143 & & \\
\hline
\end{tabular}


lineages, A. alternata ssp. arborescens, A. alternata ssp. tenuissima, and A. alternata ssp. gaisen, were identified within the section A. alternata (Armitage et al. 2015). Representative isolates of A. arborescens and $A$. gaisen were each present in a single lineage, whereas A. tenuissima, A. alternata, and A. mali were indistinct from each other and present in a third lineage. Morphological analysis supported the separation of two lineages, which differentiated isolates in A. arborescens but could not differentiate isolates in $A$. tenuissima, A. alternata, and A. mali. Although highly variable phylogenetic loci were used in their study, phylogenetic analysis assigned A. alternata and A. mali within A. alternata ssp. tenuissima instead of placing them in the discrete lineages. The authors proposed that the three lineages represent different subspecies within a single species A. alternata. Woudenberg et al. (2015) suggested 35 morphospecies including $A$. tenuissima be synonymized under A. alternata because they were indistinguishable based on multigene phylogenetic analysis. Similar to above, A. tenuissima could not be maintained in a single species and it was suggested it be merged into A. alternata. Consequently, further evaluation of the small-spored Alternaria species remains necessary.

In this study, all the selected isolates were clearly distinct from the large-spored species A. macrospora morphologically and molecularly (Lawrence et al. 2013; Pryor and Michailides 2002; Simmons 2007; Zhu and Xiao 2015). The ITS sequences of the 14 selected isolates were identical to the A. alternata reference isolate EGS 34-016 and all the selected Alternaria isolates showed A. alternata-like morphology. Thus, according to the morphological observations and molecular identification of Alternaria isolates, the causal agent of Alternaria leaf spot on cotton in southern New Mexico was identified as A. alternata. Although Alternaria leaf spot is expected to rarely cause yield loss because it typically occurs late in the season after bolls have set and are maturing, it remains of concern. Information regarding the epidemiology of the disease is necessary to establish useful information that can be readily applied should this disease become a threat to yield. Despite the tremendous effort necessitated in breeding for resistance, availability of genotypes with known resistance to Alternaria leaf spot will be advantageous in event of epidemics that may occur earlier in the growing season and potentially threaten yield.

\section{Literature Cited}

Allen, T. 2011. Cotton foliar disease and fungicide application. Mississippi State University Extension. http://www.mississippi-crops.com/2011/07/01/cottonfoliar-disease-and-fungicide-application/ (Accessed 3 Nov 2017)

Andersen, B., Krøger, E., and Roberts, R. G. 2001. Chemical and morphological segregation of Alternaria alternata, A. gaisen and A. longipes. Mycol. Res. 105: 291-299.

Andersen, B., and Thrane, U. 1996. Differentiation of Alternaria infectoria and Alternaria alternata based on morphology, metabolite profiles, and cultural characteristics. Can. J. Microbiol. 42:685-689.

Andrew, M., Peever, T. L., and Pryor, B. M. 2009. An expanded multilocus phylogeny does not resolve morphological species within the small-spored Alternaria species complex. Mycologia 101:95-109.

Anonymous. 2018. U.S. Climate Data. Retrieved 12 December 2018 from https:// www.usclimatedata.com/

Armitage, A. D., Barbara, D. J., Harrison, R. J., Lane, C. R., Sreenivasaprasad, S., Woodhall, J. W., and Clarkson, J. P. 2015. Discrete lineages within Alternaria alternata species group: identification using new highly variable loci and support from morphological characters. Fungal Biol. 119:994-1006.

Bashan, Y., Levanony, H., and Or, R. 1991. Wild beets as an important inoculum source of Alternaria alternata, a cause of leaf blight of cotton in Israel. Can. J. Bot. 69:2608-2615.

Bashi, E., Rotem, J., Pinnschmidt, H., and Kranz, J. 1983. Influence of controlled environment and age on development of Alternaria macrospora and on shedding of leaves in cotton. Phytopathol. 73:1145-1147.

Basım, E., Basım, H., Abdulai, M., Baki, D., and Öztürk, N. 2017. Identification and characterization of Alternaria alternata causing leaf spot of olive tree (Olea europaea) in Turkey. Crop Prot. 92:79-88.

Bhat, H. A., Ahmad, K., Ahanger, R. A., Qazi, N. A., Dar, N. A., and Ganie, S. A. 2013. Status and symptomatology of Alternaria leaf blight (Alternaria alternata) of Gerbera (Gerbera jamisonii) in Kashmir valley. Afr. J. Agric. Res. 8:819-823.

Cotty, P. J. 1987a. Evaluation of cotton cultivar susceptibility to Alternaria leaf spot. Plant Dis. 71:1082-1084.
Cotty, P. J. 1987b. Temperature-induced suppression of Alternaria leaf spot of cotton in Arizona. Plant Dis. 71:1138-1140.

Elfar, K., Zoffoli, J. P., and Latorre, B. A. 2018. Identification and characterization of Alternaria species associated with moldy core of apple in Chile. Plant Dis. 102:2158-2169.

Ellis, M. B., and Holliday, P. 1970. CMI descriptions of pathogenic fungi and bacteria, No. 246, Alternaria macrospora. Commonwealth Mycological Institute, Kew, U.K.

Faulwetter, R. C. 1918. The Alternaria leaf spot of cotton. Phytopathology 8: 98-105.

Gulhane, V. A., and Gurjar, A. A. 2011. Detection of diseases on cotton leaves and its possible diagnosis. Int. J. Image Proc. 5:590-598.

Hagan, A. K., and Sikora, E. J. 2013. Leaf spot management in Alabama cotton control of potash-incited leaf spot diseases and target spot. https://sites.aces. edu/group/timelyinfo/Documents/2013LeafSpotDiseasesofCottonTI.rev2.pdf (Accessed Nov. 3, 2017)

Hillocks, R. J. 1991. Alternaria leaf spot of cotton with special reference to Zimbabwe. Int. J. Pest Manage. 37:124-128.

Hillocks, R. J., and Chinodya, R. 1989. The relationship between Alternaria leaf spot and potassium deficiency causing premature defoliation of cotton. Plant Pathol. 38:502-508

Howard, D. D., Newman, M. A., and Chamber, A. Y. 1997. Soil and foliar potassium effects on Alternaria leaf spot disease in cotton. Better Crops. 81:17-19.

Kirkpatrick, T. L., and Rothrock, C. S. 2001. Compendium of Cotton Diseases American Phytopathological Society, St. Paul, MN.

Lawrence, D. P., Gannibal, P. B., Dugan, F. M., and Pryor, B. M. 2014. Characterization of Alternaria isolates from the infectoria species-group and a new taxon from Arrhenatherum, Pseudoalternaria arrhenatheria sp. nov. Mycol. Prog. 13:257-276.

Lawrence, D. P., Gannibal, P. B., Peever, T. L., and Pryor, B. M. 2013. The sections of Alternaria: formalizing species-group concepts. Mycologia 105: 530-546.

Lawrence, D. P., Rotondo, F., and Gannibal, P. B. 2016. Biodiversity and taxonomy of the pleomorphic genus Alternaria. Mycol. Prog. 15:3.

Lee, J. A. 1984. Cotton as a World Crop. Pages 1-25 in: Cotton Agronomy Monogram 24. ASA, CSSA, SSSA, Madison, WI.

Luo, Y., Hou, L., Förster, H., Pryor, B., and Adaskaveg, J. E. 2017. Identification of Alternaria species causing heart rot of pomegranates in California. Plant Dis. 101:421-427.

Nobles, M. K. 1948. Studies in forest pathology: VI. Identification of cultures of wood-rotting fungi. Can. J. Res. 26c:281-431.

Padaganur, G. M., Hiremath, R. V., and Basavaraj, M. K. 1989. Estimation of yield loss due to Alternaria leaf spot and blight in cotton. J. Indian Soc. Cotton Improve 14:144-145.

Park, D. S., Sayler, R. J., Hong, Y. G., Nam, M. H., and Yang, Y. 2008. A method for inoculation and evaluation of rice sheath blight disease. Plant Dis. 92:25-29.

Patel, J. S., and Zhang, S. 2017. First Report of Alternaria Blight of Pitahaya (Hylocereus undatus) Caused by Alternaria sp. in South Florida of the United States. Plant Dis. 101:1046.

Peever, T., Su, G., Carpenter-Boggs, L., and Timmer, L. 2004. Molecular systematics of citrus-associated Alternaria species. Mycologia 96:119-134.

Polizzotto, R., Andersen, B., Martini, M., Grisan, S., Assante, G., and Musetti, R. 2012. A polyphasic approach for the characterization of endophytic Alternaria strains isolated from grapevines. J. Microbiol. Meth. 88:162-171.

Price, T., Haggard, B., Lofton, J., Padgett, B., and Hollier, C. 2013. Cotton leaf spots. Louisiana State University AgCenter. http://louisianacrops.com/2013/ 08/02/cotton-leaf-spots/ (accessed 3 Nov 2017).

Pryor, B. M., and Bigelow, D. M. 2003. Molecular characterization of Embellisia and Nimbya species and their relationship to Alternaria, Ulocladium and Stemphylium. Mycologia 95:1141-1154.

Pryor, B. M., and Gilbertson, R. L. 2000. Molecular phylogenetic relationships amongst Alternaria species and related fungi based upon analysis of nuclear ITS and mtSSU rDNA sequences. Mycol. Res. 104:1312-1321.

Pryor, B. M., and Michailides, T. J. 2002. Morphological, pathogenic, and molecular characterization of Alternaria isolates associated with Alternaria late blight of pistachio. Phytopathol. 92:406-416.

Ridgway, R. 1912. Color standards and color nomenclature. Self-published, Washington, DC

Robeson, D. J., Strobel, G. A., and Strange, R. N. 1985. The identification of a major phytotoxic component from Alternaria macrospora as $\alpha \beta$-dehydrocurvularin. J. Nat. Prod. 48:139-141.

Rotem, J., Eidt, J., Wendt, U., and Kranz, J. 1988. Relative effects of Alternaria alternata and A. macrospora on cotton crops in Israel. Plant Pathol. 37:16-19.

Rotondo, F., Collina, M., Brunelli, A., and Pryor, B. M. 2012. Comparison of Alternaria spp. collected in Italy from apple with A. mali and other AM-toxin producing strains. Phytopathol. 102:1130-1142.

Said, J. I., Lin, Z., Zhang, X., Song, M., and Zhang, J. 2013. A comprehensive meta QTL analysis for fiber quality, yield, yield related and morphological traits, drought tolerance, and disease resistance in tetraploid cotton. BMC Genomics $14: 776$.

Sanogo, S., and Carpenter, J. 2006. Incidence of Phytophthora blight and Verticillium wilt within chile pepper fields in New Mexico. Plant Dis. 90: 291-296. 
Simmons, E. G. 1995. Alternaria themes and variations (112-144). Mycotaxon 55: 55-163.

Simmons, E. G. 1999. Alternaria themes and variations (226 - 235). Mycotaxon 70:263-323.

Simmons, E. G. 2007. Alternaria: An Identification Manual. CBS Biodiversity Series no. 6. CBS Fungal Biodiversity Centre, Utrecht, The Netherlands.

Simmons, E. G., and Roberts, R. G. 1993. Alternaria themes and variations (73). Mycotaxon 48:109-140.

Teng, P. S., and James, W. C. 2002. Disease and yield loss assessment. Pages 25-38 in: Plant Pathologist's Pocketbook. CAB International, Wallingford, U.K.

Tymon, L. S., Cummings, T. F., and Johnson, D. A. 2016. Pathogenicity and aggressiveness of three Alternaria spp. on potato foliage in the US Northwest. Plant Dis. 100:797-801.

USDA-ERS. 2012. Cotton Backgrounder. U.S. Department of Agriculture, Economic Research Service, Washington, DC.

USDA-NASS. 2017. Crop Values 2016 Summary. U.S Department of Agriculture, National Agricultural Statistics Service, Washington, DC.

Watkins, G. M. 1981. Compendium of Cotton Diseases. American Phytopathological Society, St. Paul, MN.

White, T. J., Bruns, T., Lee, S. J. W. T., and Taylor, J. W. 1990. Amplification and direct sequencing of fungal ribosomal RNA genes for phylogenetics. Pages 315-322 in: PCR Protocols: A Guide to Methods and Applications. Academic Press, San Diego, CA.

Womach, J. 2004. Cotton Production and Support in the United States. Congressional Research Service, Washington, DC.
Woodward, J. 2016. Increased incidence of Alternaria leaf spot of cotton. Texas A\&M AgriLife Extension. https://agrilife.org/texasrowcrops/ 2016/09/06/increased-incidence-of-alternaria-leaf-spot-of-cotton/ (Accessed 3 Nov 2017).

Woodward, J. E., Wheeler, T. A., and Boman, R. K. 2007. Occurrence of Alternaria Stem Blight and Leaf Spot of Cotton in West Texas. Beltwide Cotton Conferences, New Orleans, LA.

Woudenberg, J. H. C., Groenewald, J. Z., Binder, M., and Crous, P. W. 2013. Alternaria redefined. Stud. Mycol. 75:171-212.

Woudenberg, J. H. C., Seidl, M. F., Groenewald, J. Z., De Vries, M., Stielow, J. B., Thomma, B. P. H. J., and Crous, P. W. 2015. Alternaria section Alternaria: Species, formae speciales or pathotypes. Stud. Mycol. 82:1-21.

Zhao, J., Zhao, F., Jian, G., Ye, Y., Zhang, W., Li, J., and Qi, F. 2013. Intensified Alternaria spot disease under potassium deficiency conditions results in acceleration of cotton (Gossypium hirsutum L.) leaf senescence. Aust. J. Crop Sci. 7:241.

Zhu, X. Q., and Xiao, C. L. 2015. Phylogenetic, morphological, and pathogenic characterization of Alternaria species associated with fruit rot of blueberry in California. Phytopathol. 105:1555-1567.

Zhu, Y., Lujan, P., Dura, S., Steiner, R., Wedegaertner, T., Zhang, J., and Sanogo, S. 2018. Evaluation of commercial Upland (Gossypium hirsutum) and Pima ( $G$. barbadense) cotton cultivars, advanced breeding lines and glandless cotton for resistance to Alternaria leaf spot (Alternaria alternata) under field conditions. Euphytica 214:147. 